\title{
EFFECT OF METAL IONS ON THE IN VITRO AVAILABILITY OF ENOXACIN, ITS IN VIVO IMPLICATIONS, KINETIC AND ANTIBACTERIAL STUDIES
}

\author{
Najma Sultana and Erum Humza \\ Department of Pharmaceutical Chemistry, Faculty of Pharmacy, University of Karachi-75272, Pakistan \\ Muhammad Saeed Arayne* \\ Department of Chemistry, University of Karachi-75272, Pakistan \\ Urooj Haroon \\ Department of Chemistry, University of Karachi-75272 / Department of Chemistry, Federal Urdu University of Arts, Sciences and \\ Technology, Gulshan-e-Iqbal Branch, Karachi,75300, Pakistan \\ Recebido em 10/10/09; aceito em 17/8/10; publicado na web em 7/1/11
}

\begin{abstract}
The present paper describes the effect of metals ions on the in vitro availability of enoxacin (a second generation quinolone antibiotic) owing to drug-metal interaction. These interaction studies were performed at $37{ }^{\circ} \mathrm{C}$ in different $\mathrm{pH}$ environments simulating human body compartments and were studied by UV spectroscopic technique. In order to determine the probability of these reactions different kinetic parameters (dissolution constants $(\mathrm{K})$ and free energy change $(\Delta \mathrm{G})$ ) for these reactions were also calculated. It is proposed that the structure of enoxacin contains various electron donating sites which facilitate its binding with metallic cations forming chelates. Hence taking food products, nutritional supplements or multivitamins containing multivalent cations at the same time as enoxacin, could reduce the absorption of the drug into the circulation and thus would decrease the effectiveness of the drug. In addition, the MIC of enoxacin for various microorganisms before and after interaction with metal ions was calculated which in most cases was increased which possibly could impair the clinical efficacy of the drug.
\end{abstract}

Keywords: metal interaction; enoxacin; UV spectroscopy.

\section{INTRODUCTION}

Study of interaction between drugs and metals is an active research area in bioinorganic chemistry. It is well known that metal ions might play a vital role during the biological process of drug utilization in the body. ${ }^{1,2}$

Recent studies indicate an important role of metal ions in the mechanism of action of quinolones. From investigations of the structure and activity of certain quinolones and the interaction of their $\mathrm{Cu}$ (II) complexes on a DNA model, it was suggested that the intercalation of the quinolone complexed to a metal is an important step in their mechanisim of action. ${ }^{3}$

Although reports indicate that the coordination of quinolones to metal ions such as $\mathrm{Mg}^{2+}$ and $\mathrm{Ca}^{2+}$ appears to be important for the activity of the quinolone antibiotics, ${ }^{4}$ it has a detrimental effect on their absorption. ${ }^{5}$ The interaction of metal ions with diverse deprotonated quinolones as ligands has been thoroughly studied. ${ }^{6}$ Early studies by Nakano demonstrated the ability of the quinolone naldixic acid to complex a variety of metal ions. ${ }^{7}$

Literature review reveals that there are few studies on the interaction of metal ions with enoxacin. ${ }^{8}$ There is evidence of the formation of complexes of enoxacin with $\mathrm{Mg}$ and $\mathrm{Ca}$ cations at $\mathrm{pH} 7.4$, the binding sites being first the carbonyl and carboxyl groups and then the piperazine N4 atom. ${ }^{9}$ In our previous studies we have synthesized $\left(\mathrm{Fe}^{\mathrm{III}}, \mathrm{Cu}^{\mathrm{II}}, \mathrm{Ni}^{\mathrm{II}}, \mathrm{Mn}^{\mathrm{II}}\right)$ complexes of enoxacin and have evaluated the effect of metal ions on the antibacterial and anti-inflammatrory activity of enoxacin. ${ }^{10}$ In continuation of our research program, to study the interaction of enoxacin with various metals, herein we report the

\footnotetext{
*e-mail: msaraynel1@gmail.com
}

effect of metal interactions on the in vitro availability of enoxacin (Figure 1) by UV spectroscopy. Previously we have used similar technique to predict drug-drug interactions in vitro. ${ }^{11}$ These studies were performed in different $\mathrm{pH}$ environments; simulated gastric juice $(\mathrm{pH}$ 1.5) and simulated intestinal environment ( $\mathrm{pH} 6.8$ and 9). ${ }^{12}$ Kinetic parameters of possible interactions were also calculated. Moreover the MIC of enoxacin before and after interaction with metal ions was also evaluated and compared with the parent.<smiles>CCn1cc(C(=O)O)c(=O)c2cc(F)c(N3CCNCC3)nc21</smiles>

Figure 1. Structure of enoxacin

\section{RESULT AND DISCUSSION}

\section{Spectrophotometric analysis}

The calculated molar absorptivites of enoxacin in $\mathrm{pH} 1.5,6.8$ and 9 at 268-262 nm were 32040, 24170 and 19249 and at 339-336 nm were 8160,23205 and 19165 moles $^{-1} \mathrm{~L} \mathrm{~cm}^{-1}$. The absorption spectra of enoxacin contain two bands, at 268 (Chromophore I) and $339 \mathrm{~nm}$ (Chromophore II) (pH 1.5) slightly shifted to 262 and $336 \mathrm{~nm}$ in $\mathrm{pH}$ 6.8 and 9 respectively. The absorption of chromophore $\mathrm{I}$ is due to the $\mathrm{C}_{2}=\mathrm{C}_{3} \pi-\pi^{*}$ transition which is in conjugation between the two auxochromic groups i.e. $\mathrm{N}_{1}$ nitrogen containing the non-bonding electrons and the carboxylic group at $\mathrm{C}_{3}$ carbon. While the absorption 
<smiles>CCn1cc(C(=O)[O-])c(=O)c2cc(F)c(N3CCNCC3)nc21</smiles>

Figure 2. Ionization of enoxacin

of chromophore II results from $\mathrm{C}_{6}=\mathrm{C}_{7} \pi-\pi^{*}$ transition which is in conjugation between the $\mathrm{N}_{1}$ nitrogen of piperazinyl ring and extends to the carbonyl group at $\mathrm{C}_{4}$.

Availability of enoxacin was calculated at 268-262 and 339-336 $\mathrm{nm}$ in $\mathrm{pH} 1.5,6.8$ and 9 using Beer Equation $(\mathrm{A}=\varepsilon \mathrm{bc})$. After $3 \mathrm{~h}$, individual availability of the drug was nearly $100 \%$ in all dissolution mediums at $37^{\circ} \mathrm{C}$. However decrease in the concentration of enoxacin was observed in presence of metals in all $\mathrm{pH}$ mediums. This is because enoxacin ligand interacted with the metal ions possibly leading to the formation of drug metal chelates. ${ }^{13}$ It was further observed that the ability of enoxacin to interact with metal ion was $\mathrm{pH}$ dependent and was greater in extreme $\mathrm{pH}$ conditions i.e. $\mathrm{pH} 1.5$ and $\mathrm{pH} 9$.

At $268-262 \mathrm{~nm}$, the concentration of enoxacin in $\mathrm{pH} 1.5$, in presence of all the metal ions except $\mathrm{Mg}^{\mathrm{II}}$ was decreased by $30 \%$ as compared to the availability of the drug alone, while in $\mathrm{pH} \mathrm{9,} \mathrm{a}$ diminution of $20-25 \%$ in ligand concentration was observed. In $\mathrm{pH}$ 6.8 , the concentration of enoxacin in presence of all the metal ions was slightly affected whereby a reduction of $10-15 \%$ was observed. Similar results were obtained at 339-336 nm. In $\mathrm{pH} 1.5$ and 9 the concentration of enoxacin was considerably depressed by $25-30 \%$ while a $10-15 \%$ reduction was observed in $\mathrm{pH} 6.8$.

Enoxacin $(\mathrm{EnoH})$ like other fluoroquinolone analogues with the piperazinyl group in the 7-position contain two relevant ionizable functional groups; the 3-carboxyl group and $\mathrm{N}_{4}$ of the piperazine substituent.

At low $\mathrm{pH}$ values, both the 7-piperazinyl group and 3-carboxyl group are protonated; $\mathrm{EnoH}_{2}{ }^{+}$, in neutral $\mathrm{pH}$ the drug exists as an intermediate zwitterion; $\mathrm{EnoH}^{ \pm}$, whereas at high $\mathrm{pH}$ values, the drug exists as a basic anion; Eno-. Since a carboxyl group is a stronger acid than the ammonium group, ${ }^{6}$ the first ionization constant of enoxacin is reported at $(\mathrm{pKa} 1 ; 6.32)$ which corresponds to the dissociation of a proton from the carboxyl group of enoxacin while ( $\mathrm{pKa} 2 ; 8.62)$ corresponds to the dissociation of proton from N4 in the piperazinyl group $^{14}$ (Figure 2).

In previous studies, metal complexes of quinolones isolated from acidic media usually contain singly and/or doubly protonated quinolones that are incapable of bonding to the metal ion and in these cases only electrostatic interaction was observed between the drug and the metal ions. ${ }^{15,16}$ Here in we also propose that ionic interaction existed between the drug and metal ion in acidic medium. At low $\mathrm{pH}$, the ring carbonyl oxygen of enoxacin is protonated ${ }^{17}$ or the hydrogen atom of the carboxylic group is hydrogen bonded to the carbonyl oxygen atom, ${ }^{18}$ giving it a partial positive charge. As the carboxylic group is not deprotonated, the consequence is that this part of the molecule is unable to bind to the metal (no significant shift of the absorption peak of Chromophore II). While the enoxacin molecule is also protonated at the $\mathrm{N}_{4}$ nitrogen atom of piperazinyl ring, thus its charge is +2 or +1 respectively. Hence, it is proposed that chemical species formed in acidic media are ionic in nature, consisting of protonated enoxacin cation and chlorometalate anion. ${ }^{15}$ Their UV spectra in comparison with the drug alone indicates a red shift of absorption band at 268-262 $\mathrm{nm}$ which is due to charge stabilization of intra-ligand $\mathrm{C}_{6}=\mathrm{C}_{7} \pi \rightarrow \pi^{*}$ transitions upon interaction with the metal ions. ${ }^{19}$
The proposed mechanism of interaction between enoxacin and metal cations in neutral and basic medium is chelation between the metal and the 4-oxo and adjacent 3-carboxyl groups. In their spectra, a red shift of the absorption band at 339-336 nm was observed. The lone pair electrons on $\mathrm{N}_{1}$ nitrogen of enoxacin can conjugate with the 3-carboxylate anion through carbons $\mathrm{C}_{2}=\mathrm{C}_{3}$ and this anionic group is destabilized. The intra-molecular electron transfer from $\mathrm{N}_{1}$ of the piperazinyl group to 4-keto oxygen will facilitate complex formation reaction between drugs and metal cations..$^{20}$ When divalent cations are complexed between carboxylate anion and 4-keto oxygen, this conjugation will occur more effectively and the energy levels of both the ground and excited states will be stabilized. It is proposed that such species are neutral in nature and their charges are compensated by chloride ions present in the medium. ${ }^{21}$ The degree of complexation was more in basic medium as compared to neutral medium. This is probably because in $\mathrm{pH} 6.8$ enoxacin exists as zwitterionic form and the positive charge on the zwitterion makes it difficult for the metal cations to approach the binding site. ${ }^{14}$

The variation observed in dissolution constants $(\mathrm{K})$ of the reaction in $\mathrm{pH} 1.5,6.8$ and 9 were also calculated (Tables 1 and 2).

Table 1. Dissolution constant $(\mathrm{K})$ and $\Delta \mathrm{G}$ of enoxacin-metal interactions

\begin{tabular}{lcccccc}
\hline \multicolumn{2}{c}{$\mathrm{pH} 1.5$} & \multicolumn{3}{c}{$\mathrm{pH} 6.8$} & \multicolumn{2}{c}{$\mathrm{pH} 9$} \\
Complex & $\mathrm{K}_{268}$, & $\Delta \mathrm{G}$ & $\mathrm{K}_{262}$ & $\Delta \mathrm{G}$ & $\mathrm{K}_{262}$ & $\Delta \mathrm{G}$ \\
\hline Enox $+\mathrm{Mg}$ & 0.010 & 11.61 & 0.014 & 11.12 & 0.014 & 10.31 \\
Enox $+\mathrm{Ca}$ & 0.010 & 11.13 & 0.014 & 12.07 & 0.016 & 10.29 \\
Enox $+\mathrm{Cr}$ & 0.012 & 11.51 & 0.012 & 11.11 & 0.013 & 12.20 \\
Enox $+\mathrm{Fe}^{+2}$ & 0.011 & 10.83 & 0.013 & 11.90 & 0.012 & 11.15 \\
Enox $+\mathrm{Co}$ & 0.010 & 11.51 & 0.014 & 11.89 & 0.015 & 10.34 \\
Enox $+\mathrm{Zn}$ & 0.017 & 10.89 & 0.014 & 11.96 & 0.013 & 10.62 \\
Enox $+\mathrm{Cd}$ & 0.127 & 11.81 & 0.014 & 11.42 & 0.015 & 10.45 \\
\hline
\end{tabular}

Table 2. Dissolution constant $(\mathrm{K})$ and $\Delta \mathrm{G}$ of enoxacin-metal interactions

\begin{tabular}{lcccccc}
\hline pH 1.5 & & \multicolumn{3}{c}{$\mathrm{pH} 6.8$} & \multicolumn{3}{c}{$\mathrm{pH} 9$} \\
Complex & $\mathrm{K}_{339}$, & $\Delta \mathrm{G}$ & $\mathrm{K}_{336}$ & $\Delta \mathrm{G}$ & $\mathrm{K}_{336}$ & $\Delta \mathrm{G}$ \\
\hline Enox $+\mathrm{Mg}$ & 0.0003 & 20.47 & 0.014 & 11.05 & 0.01 & 11.87 \\
Enox $+\mathrm{Ca}$ & 0.002 & 15.77 & 0.010 & 11.83 & 0.011 & 11.62 \\
Enox $+\mathrm{Cr}$ & 0.0069 & 12.80 & 0.009 & 12.19 & 0.012 & 11.39 \\
Enox $+\mathrm{Fe}^{+2}$ & 0.0062 & 13.07 & 0.009 & 12.18 & 0.013 & 11.19 \\
Enox $+\mathrm{Co}$ & 0.0053 & 13.49 & 0.008 & 12.46 & 0.010 & 11.80 \\
Enox $+\mathrm{Zn}$ & 0.0048 & 13.76 & 0.009 & 12.43 & 0.011 & 11.69 \\
Enox $+\mathrm{Cd}$ & 0.0046 & 13.87 & 0.009 & 12.01 & 0.011 & 11.57 \\
\hline
\end{tabular}

The spontaneity of the proposed interactions was determined from the calculation of the free energy change $(\Delta \mathrm{G})$ for these reactions at constant temperature. The positive value of $\Delta \mathrm{G}$ (Tables 1 and 2) showed that these interactions were non spontaneous. If $\Delta \mathrm{G}$ is large and positive i.e. about $100 \mathrm{~kJ}$ the reaction is suppose to be hardly occurring in the 
forward direction. If $\Delta \mathrm{G}$ is small and positive i.e. about $10 \mathrm{KJ}$, the reaction is suppose to reach equilibrium..$^{22}$ In our interaction studies, $\Delta \mathrm{G}$ ranged from $10-20 \mathrm{KJ}$, indicating that the complexation reaction was possible and would attain equilibrium in which enoxacin ligand would be present in both forms i.e. as a free ligand as well as bonded to the metal ion. This inference agrees well with the availability data which showed the concentration of free enoxacin which would be at equilibrium with enoxacin bonded to the metal ions.

$$
\text { Metal ion }+ \text { enoxacin } \rightleftharpoons[\text { M)enoxacin })]
$$

Decrease in the availability of enoxacin to a certain extent was observed which indicates that the drug was not completely utilized in complex formation.

\section{Antibacterial study}

The MIC of enoxacin after interaction with the metals was found to be elevated for most of the strains as compared to the parent drug (Tables 3-4). The increase in the MICs for most of the organisms was 2-4 folds. However, for Salmonella typhi, Bacillus subtilis and Proteus mirabilis, the MICs of enoxacin increased up to 10 folds after interaction with $\left(\mathrm{Cd}^{\mathrm{II}}\right),\left(\mathrm{Cr}^{\mathrm{III}}, \mathrm{Zn}^{\mathrm{II}}\right)$ and $\left(\mathrm{Ca}^{\mathrm{II}}, \mathrm{Cd}^{\mathrm{II}}\right)$ metal ions respectively.

\section{EXPERIMENTAL}

\section{Materials and equipment}

Enoxacin base was a kind gift from Zafa Pharmaceutical Laboratories Ltd., Karachi, Pakistan. The metals used were of analytical grade. All the glassware was washed with chromic acid followed by a thorough washing with de-ionized water which was freshly prepared in the laboratory.

Dissolution test apparatus manufactured according to B.P 2006 standard, ${ }^{23}$ with little modification ${ }^{24}$ was used for the interaction studies. UV/Visible spectrophotometer (Shimadzu 1601 coupled with a P IV - PC and loaded with UVPC version 3.9, software) was used to quantitate the drug contents.

\section{Molar absorptivity of enoxacin}

$1 \mathrm{M}$ solution of enoxacin was prepared individually in buffers of $\mathrm{pH} \mathrm{1.5,} 6.8$ and 9. From these primary solutions, stock solutions of $0.1 \mathrm{M}$ of enoxacin were prepared. The stock solutions were further diluted to obtain working standard solutions in the concentration range of 0.01-0.055 M. Absorbance of all these solutions was measured by the UV/Visible spectrophotometer in the region 360-200 nm. At pH 1.5 the absorption bands of enoxacin was observed at 268 and 339 $\mathrm{nm}$ whereas for buffers of $\mathrm{pH} 6.8$ and 9 these bands were recorded at 262 and $336 \mathrm{~nm}$.

The calibration curve was obtained by plotting the absorbance of these solutions versus concentration. Beer Lambert's law was obeyed at all concentration and $\mathrm{pH}$, and molar absorptivities of enoxacin at its $\lambda$ max were calculated in all $\mathrm{pH}$ mediums using Beer's equation.

\section{Availability studies}

The in vitro availability of enoxacin was obtained by using the dissolution apparatus as discussed above. The dissolution fluid was buffers of $1000 \mathrm{~mL}$ of $\mathrm{pH}$ 1.5, 6.8 and 9. 1 mmole of enoxacin was

Table 3. Minimum inhibitory concentration $(\mu \mathrm{g} / \mathrm{mL})$

\begin{tabular}{|c|c|c|c|c|c|c|}
\hline S. No & Microorganisms & enoxacin & Mg complex & Ca complex & Cr complex & Fe complex \\
\hline 1 & Staphylococcus aureus & 4.0 & 8.0 & 8.0 & 8.0 & 16 \\
\hline 2 & Streptococcus pyogenes & 16 & 32 & 32 & 32 & 32 \\
\hline 3 & Streptococcus pneumoniae & 16 & 16 & 32 & 32 & 32 \\
\hline 4 & Entreococcus & 16 & 32 & 16 & 32 & 32 \\
\hline 5 & Escherichia coli & 0.5 & 1.0 & 1.0 & 1.0 & 1.0 \\
\hline 6 & Salmonella typhi & 0.1 & 0.5 & 0.5 & 0.2 & 0.5 \\
\hline 7 & Pseudomonas aeruginosa & 4.0 & 8.0 & 8.0 & 8.0 & 8.0 \\
\hline 8 & Bacillus subtilis & 0.2 & 0.2 & 1.0 & 2.0 & 0.5 \\
\hline 9 & Klebsiella pneumoniae & 0.2 & 0.5 & 1.0 & 0.5 & 0.5 \\
\hline 10 & Proteus mirabilis & 0.2 & 0.2 & 2.0 & 1.0 & 1.0 \\
\hline
\end{tabular}

Table 4. Minimum inhibitory concentration $(\mu \mathrm{g} / \mathrm{mL})$

\begin{tabular}{|c|c|c|c|c|c|}
\hline No. & Microorganisms & enoxacin & Co complex & Zn complex & Cd complex \\
\hline 1 & Staphylococcus aureus & 4.0 & 8.0 & 16 & 8.0 \\
\hline 2 & Streptococcus pyogenes & 16 & 16 & 32 & 32 \\
\hline 3 & Streptococcus pneumoniae & 16 & 16 & 32 & 32 \\
\hline 4 & Entreococcus & 16 & 32 & 32 & 32 \\
\hline 5 & Escherichia coli & 0.5 & 2.0 & 2.0 & 0.5 \\
\hline 6 & Salmonella typhi & 0.1 & 0.5 & 0.5 & 1.0 \\
\hline 7 & Pseudomonas aeruginosa & 4.0 & 4.0 & 8.0 & 8.0 \\
\hline 8 & Bacillus subtilis & 0.2 & 1.0 & 2.0 & 1.0 \\
\hline 9 & Klebsiella pneumoniae & 0.2 & 0.2 & 1.0 & 1.0 \\
\hline 10 & Proteus mirabilis & 0.2 & 0.5 & 0.5 & 2.0 \\
\hline
\end{tabular}


introduced in dissolution medium previously maintained at $37{ }^{\circ} \mathrm{C}$. Samples were withdrawn periodically with an interval of $15 \mathrm{~min}$ for $180 \mathrm{~min}$. The volume of dissolution fluid was maintained by adding an equal amount of dissolution fluid withdrawn, which had previously been maintained at the same temperature in the same bath. The absorbance of all the aliquots withdrawn was measured at 268-262 and 339-336 $\mathrm{nm}$. Using the epsilon values and the absorbance, the availability of enoxacin at each time interval was calculated.

\section{Interaction studies}

In testing the effect of metals on the dissolution behavior of the antibiotic, 1 mmole of metals were added to the dissolution medium maintained at $37{ }^{\circ} \mathrm{C}$ along with 1 mmole of drug at the start of the experiment and aliquots were drawn similarly. The absorbance of all the aliquots was measured at (268-262 and 339-336 nm) that gave the drug availability at that particular time. Results were satisfactorily reproducible.

\section{Antibacterial activities}

The MIC of enoxacin before and after interaction with metals was assessed by broth dilution method. ${ }^{25}$ For this purpose $1 \mathrm{~mL}$ of nutrient broth was taken in 8 test tubes and autoclaved for $15 \mathrm{~min}$ at $121 \mathrm{lbs}$. The solution of enoxacin according to its reported MIC (minimum inhibitory concentration ${ }^{26}$ was prepared in the concentration range of $32-0.125 \mu \mathrm{g} / \mathrm{mL}$. Initially $0.001 \mathrm{mM}$ solution of enoxacin $(32 \mu \mathrm{g} / \mathrm{mL})$ and metals of similar concentration were prepared in methanol. Equal volumes of solutions of enoxacin and metals were mixed in test tubes and refluxed at $70{ }^{\circ} \mathrm{C}$ until the disappearance of the drug (monitored by TLC). After interaction, $1 \mathrm{~mL}$ of the sample was poured in the first set of test tubes containing $1 \mathrm{~mL}$ of nutrient broth (previously autoclaved for $15 \mathrm{~min}$ at $121 \mathrm{lbs}$ ). After which serial dilutions were made in the concentration range of $0.125-32 \mu \mathrm{g} / \mathrm{mL}$, followed by the addition of $0.2 \mathrm{~mL}$ of culture in each test tubes. The test tubes were incubated for $24 \mathrm{~h}$ at $37^{\circ} \mathrm{C}$ and observed for turbidity.

\section{CONCLUSION}

From above studies we conclude that availability of enoxacin was noticeably decreased in the presence of metal ions. This decrease in the availability is attributed to the ability of the drug to complex metal ion. The proposed drug-metal interactions could interfere substantially with the intestinal absorption of enoxacin owing to the lower solubility of the chelates in intestinal tract. ${ }^{27}$ Further, the MICs of enoxacin after interaction with selected metal ions were found to be elevated for most of the strains as compared to the drug. Consequently, it is suggested that concomitant administration of enoxacin with antacids, food products, nutritional supplements and multivitamins containing multivalent cations could impair the clinical efficacy of the drug and reduce its bioavailability.

\section{ACKNOWLEDGMENT}

The authors acknowledge Higher Education Commission of Pakistan for providing financial support to Ms. U. Haroon under Indigenous Ph.D. 5000 Scholarship Program Batch III.

\section{REFERENCES}

1. Liu, J.; Wang, E. B. J.; Peng, Y. S.; J. Rare Earths 1999, 17, 139.

2. Chakrabarti, S.; Dasgupta, D.; Bhattacharyya, D.; J. Biol. Phys. 2000, 2, 203.

3. Robles, J.; Polo, J. M.; Álvarez, L.; Hinojosa, L.; Mendoza-Díaz, G.; Metal Based Drugs 2000, 7, 301.

4. Efthimiadou, E. K.; Psomas, G.; Sanakis, Y.; Katsaros, N.; Karaliota, A.; J. Inorg. Biochem. 2007, 101, 525.

5. Motoya, I.; Niyashita, M.; Kawachi, A.; Yamada, K.; J. Pharm. Pharmacol. 2000, 52, 397.

6. Turel, I.; Coord. Chem. Rev. 2002, 232, 27.

7. Nakano, M.; Yamamoto, M.; Arita, T.; Chem. Pharm. Bull. 1978, 26, 1505.

8. Jiménez, N.; Perelló, L.; Ortiz, R.; Alzuet, G.; González-Álvarez, M.; Cantón, E.; Liu-González, M.; García-Granda, S.; Pérez-Priede, M.; J. Inorg. Biochem. 2005, 99, 677.

9. Lecomte, S.; Chenon, M.; Int. J. Pharm. 1996, 139, 105.

10. Arayne, S.; Sultana, N.; Haroon, U.; Mesaik, M. A.; Bioinorganic Chemistry and Applications (2009), doi: 0.1155/2009/914105.

11. Arayne, M. S.; Sultana, N.; Rizvi, S. B. S.; Haroon, U.; Med. Chem. Res. (2009), doi: 10.1007/s00044-009-9225-5.

12. Dedlovskaya, V. I.; B. Exp. Biol. Med+ 1968, 66, 1292.

13. Jaehde, U.; Soergel, F.; Stephan, U.; Schunack, W.; Antimicrob. Agents Chemother. 1994, 38, 1129.

14. Park, H. R.; Chung, K. W.; Lee, H. C.; Lee, J. K.; Bark, K. M.; Bull. Korean Chem. Soc. 2000, 21, 849.

15. Turel, I.; Leban, I.; Klintschar; Bukovec, N.; Zalar, S.; J. Inorg. Biochem. 1997, 66, 77.

16. Turel, I.; Leban, I.; Bukovec, N.; J. Inorg. Biochem. 1997, 66, 241.

17. Timmers, K.; Sternglanzt, R.; Bioinorg. Chem. 1978, 9, 145.

18. Turel, I.; Leban, I.; Zupan, M.; Bukovec, P.; Gruber, K.; Acta Crystallogr., Sect. C: Cryst. Struct. Commun. 1996, 52, 2443.

19. Eleni, E.; Sanakis, Y.; Katsaros, N.; Karaliota, A.; Psomas, G.; Polyhedron 2007, 26, 1148.

20. Park, H. R.; Lee, H. C.; Kim, T. H.; Lee, J. K.; Yang, K. Y.; Bark, K. M.; Photochem. Photobiol. 2000, 71, 281.

21. Sagdinc, S.; Bayar, S.; J. Mol. Struct. 2004, 691, 107.

22. Hill, J. W.; Petruci, R. H.; General Chemistry, Prentice Hall: New Jersey, 1996.

23. British Pharmacopia, 2006, Her Majesty Stationary Office, 2, p. A 143.

24. Iftikhar, A.; Arayne, M. S.; Sultana, N.; Pak. J. Pharm. Sci. 2005, 18, 55.

25. Thrupp, L. D.; Antibiotics in laboratory medicine, The William \& Wilkins Co: Baltimore, 1980.

26. Committee for Revision of MIC Determination Method, Revision of minimal inhibitory concentration (MIC) determination method; Chemotherapy 1981, 29, 76.

27. Pletz, M. W.; Petzold, P.; Allen, A.; Antimicrob. Agents Chemother. 2003, $47,2158$. 